\title{
COMPARISON OF THE BEHAVIOR OF FIBER AND MESH REINFORCED SOILS
}

\author{
Y. C. Fung ${ }^{1}$ and Shenbaga. R. Kaniraj ${ }^{1}$ \\ ${ }^{1}$ Department of Mechanical and Manufacturing, Universiti Malaysia Sarawak, 93000, Kota Samarahan, Sarawak, Malaysia
}

Date received: 26/6/17, Date accepted: 20/8/17

Corresponding author's email: fungyuetcher@yahoo.com

\begin{abstract}
Soft soil does not have good soil properties and is not suitable for constructing pavement structures as shear strength is required to resist the shear stress developed by traffic loading. To increase shear strength in this study, lime is used as the soil stabilizing agent and fiber and mesh are used as the soil reinforcement materials. The proper amount of lime added to soil will increase the shear strength as the lime-treated soil will decrease moisture susceptibility and migration. Shear strength of the lime-treated soil can be further improved by adding reinforcement materials such as fiber and mesh. The reinforcement materials will interlock with groups of particles and provide tensile strength to the soil matrix. The type of soil used in this study is high plasticity elastic silt with sand which is classified using the Unified Soil Classification System (USCS). Quicklime (calcium oxide) is used in this study at the minimum amount required for stabilizing the soil, which is 9\%. The amount of fiber and mesh added to the soil sample is $0.5 \%$ of the dry weight of the soil used. Cylindrical samples were prepared with a moisture content of 22\% (OMC) for untreated soil and 21\% (OMC) for lime-treated soil samples. The lime-treated soil samples were cured for 7, 14, 28, 56, 90 and 120 days. Unconfined compression tests were conducted to determine unconfined compressive strength (UCS) and stress-strain characteristics. The unconfined compressive strength of the lime-treated samples increased as curing period increased but the failure strain decreased. The UCS and failure strain for reinforced lime-treated soil samples are higher than the unreinforced lime-treated soil samples.
\end{abstract}

Keywords: Soil stabilization, soil reinforcement, lime, fiber, mesh.

\subsection{INTRODUCTION}

Sarawak, especially the Kuching Division, is developing rapidly. Many buildings, roads and other infrastructure need to be constructed. Sarawak's lands are composed of soft soil. Soil reinforcement or soil stabilization must be done before infrastructure can be built. Discovering new and more efficient soil stabilization and soil reinforcement methods are crucial to overcome these soft soil issues.

Good soil properties such as high shear strength, high stiffness modulus and high durability are essential for road pavement construction. Soil stabilization is a technique introduced with the aim of improving the physical and chemical characteristics of soil so that the soil is able to meet the requirements of specific engineering projects [1]. Cement, lime and mineral additives such as fly ash, silica fume, and rice husk ash are added to the soil to stabilize it [2]. Fiber and some natural materials such as oil palm empty fruits bunch are commonly used as soil reinforcement materials [3].

This study compares the behavior of untreated soil, stabilized soil, and fiber and mesh reinforced soil. Unconfined compression test is conducted on (a) untreated, (b) lime treated, (c) fiber reinforced lime treated, (d) mesh reinforced, (e) fiber reinforced lime treated soil and (f) mesh reinforced lime treated soil samples to investigate the effectiveness of fiber and mesh reinforcement on treated and untreated soils. The lime treated soil samples were cured for 7, 14, 28, 56, 90 and 120 days before unconfined compression test were carried out.

\subsection{MATERIALS}

The materials used in this research were high plasticity elastic silt with sand (MH) soil, Calcium Oxide (quicklime), fiber and mesh. The soil used in this study was collected at the road side of Kuching-Kota 
Samarahan Expressway at $1^{\circ} 28^{\prime} 58.2^{\prime \prime N} 110^{\circ} 24^{\prime} 45.0^{\prime \prime E}$. The Calcium Oxide (quicklime) was manufactured by SIGMA-ALDRICH. The fiber element used in this study is cut from an insect net. The length of the fiber is $7 \mathrm{~mm}$ with diameter of $1 \mathrm{~mm}$. The mesh element used in this study is also cut from the same insect net as the fiber. The mesh was cut into a diamond shape $7 \mathrm{~mm}$ to each side, with $2 \mathrm{~mm} \mathrm{x}$ $2 \mathrm{~mm}$ openings.

\subsection{EXPERIMENTAL PROCEDURES}

\subsection{Mix proportion and curing period}

The fiber reinforced soil sample contained $0.5 \%$ fiber, the mesh reinforced soil sample contained $0.5 \%$ mesh and the lime treated soil sample contained $9 \%$ lime. The initial consumption of lime test is very important for determination of the amount of lime required for soil stabilization. The initial consumption of lime, which is the amount of lime consumed in the initial ion exchange reaction, is the minimum lime content required for the soil sample to achieve a permanent gain in strength [4]. Soil samples were mixed with 5\% to $14 \%$ lime and tested for $\mathrm{pH}$ value. The samples recording $\mathrm{pH}$ values in the range of 12.35 to 12.45 at $25^{\circ} \mathrm{C}$ with the least percentage of lime content were selected as the initial consumption of lime. The lime treated soil samples were cured for 7, 14, 28, 56, 90 and 120 days before unconfined compression tests were carried out.

\subsection{Test conducted}

Unconfined compression test was done to determine the shear parameters of cohesive soil. This test is carried out on a cylindrical specimen. The height of the specimen must be twice the diameters of the specimen. Specimens of $35 \mathrm{~mm}$ in diameter and $70 \mathrm{~mm}$ in height were used. The test was done by referring to BS 1377: Part 7: 1990 [5].

\subsection{RESULTS AND ANALYSIS}

\subsection{Unconfined compressive strength}

The unconfined compression strength (UCS) test is a type of unconsolidated-undrained triaxial test in which the confining pressure is equal to $0 \mathrm{kPa}$. This test was done on untreated samples, treated samples, reinforced and unreinforced samples by referring to BS 1377: Part 7: 1990 [5].

The average UCS strength and failure strength of untreated soil samples were $81.68 \mathrm{kN} / \mathrm{m}^{2}$ and $4.19 \%$ respectively. For fiber reinforced untreated soil samples, the average UCS and average failure strain were $107.26 \mathrm{kPa}$ and $5.87 \%$ respectively. For mesh reinforced untreated soil samples, the average UCS and average failure strain were $105.81 \mathrm{kPa}$ and $5.24 \%$ respectively. For lime treated soil, fiber reinforced lime treated soil and mesh reinforced lime treated soil samples, the UCS increased as the curing period increased, whereas the average failure strain decreased as the curing period increased. The average UCS for lime treated soil samples was higher compared to untreated soil samples. The average UCS and failure strain of reinforced lime treated soil samples were higher compared to lime treated soil samples. Hence, lime was able to increase the UCS of the soil sample but reduce the failure strain as curing period increased. Fiber and mesh reinforcement are able to increase the UCS and untreated and lime treated soil samples. Figures 1-6 show the result of variation of axial stress (kPa) against axial strain for untreated, fiber reinforced, mesh reinforced, lime treated, lime treated fiber reinforced and lime treated mesh reinforced soil specimens. 


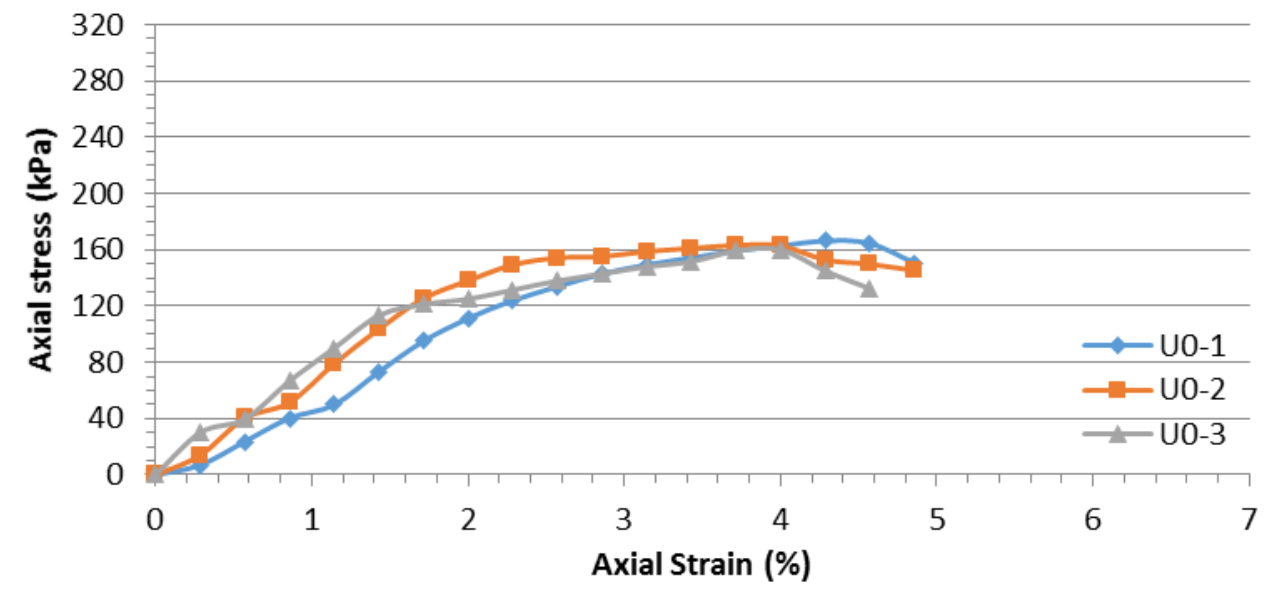

Figure 1 Variation of axial stress $(\mathrm{kPa})$ against axial strain for untreated soil specimens

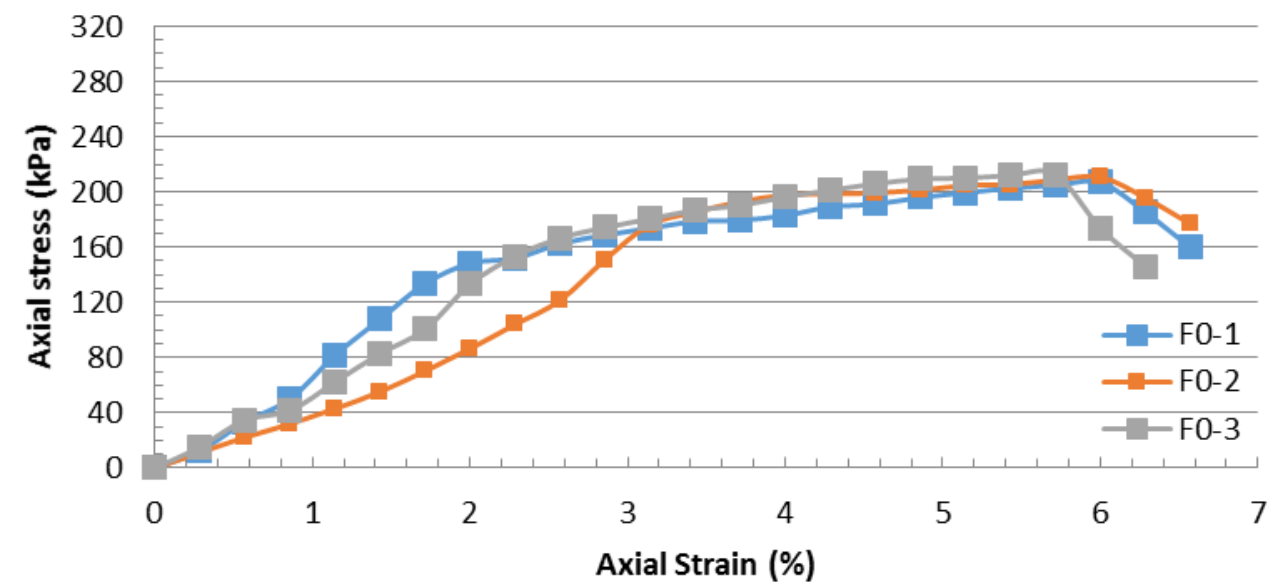

Figure 2 Variation of axial stress $(\mathrm{kPa})$ against axial strain for fiber reinforced soil specimens

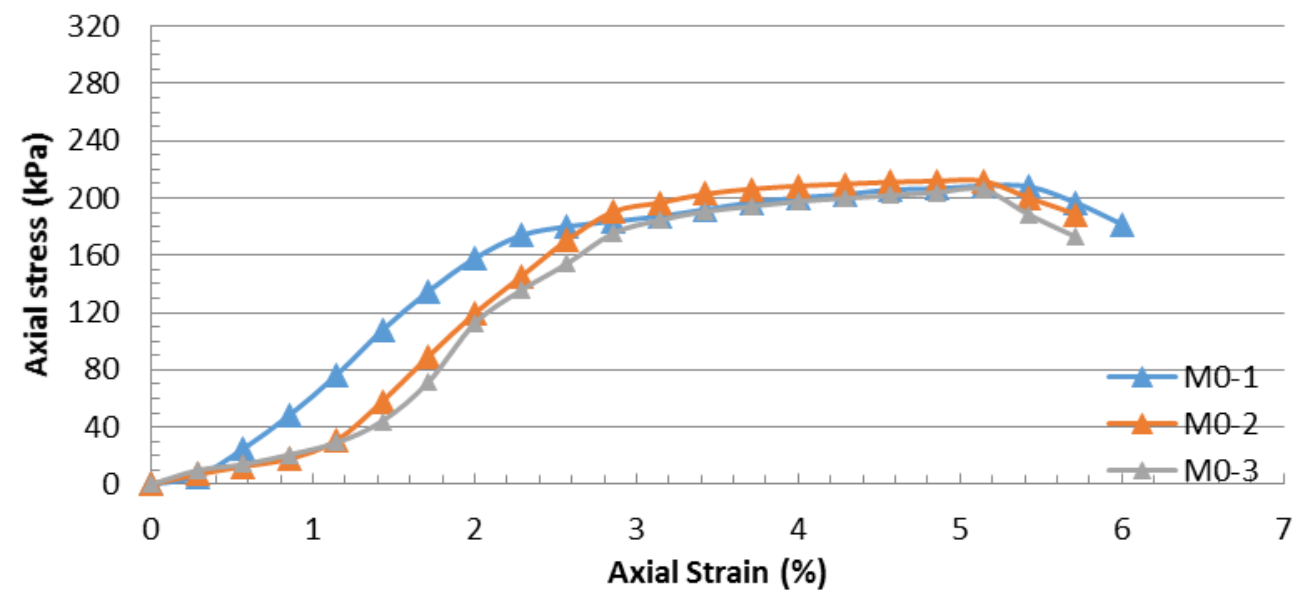

Figure 3 Variation of axial stress $(\mathrm{kPa})$ against axial strain for mesh reinforced soil specimens 


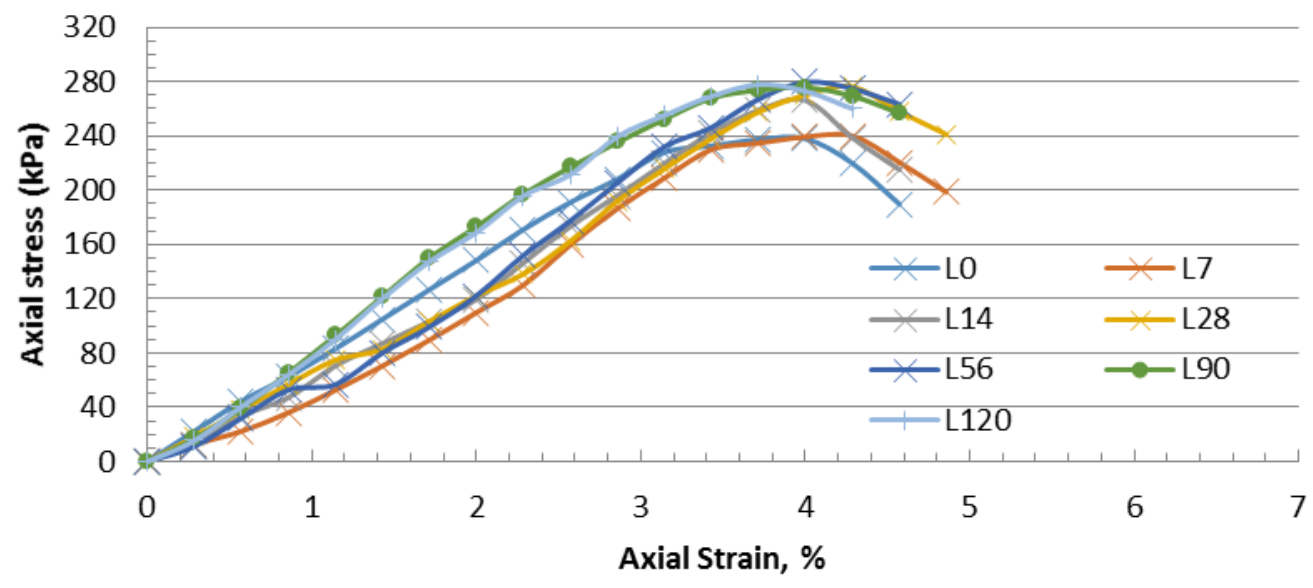

Figure 4 Variation of axial stress $(\mathrm{kPa})$ against axial strain for lime treated soil specimens at different curing periods

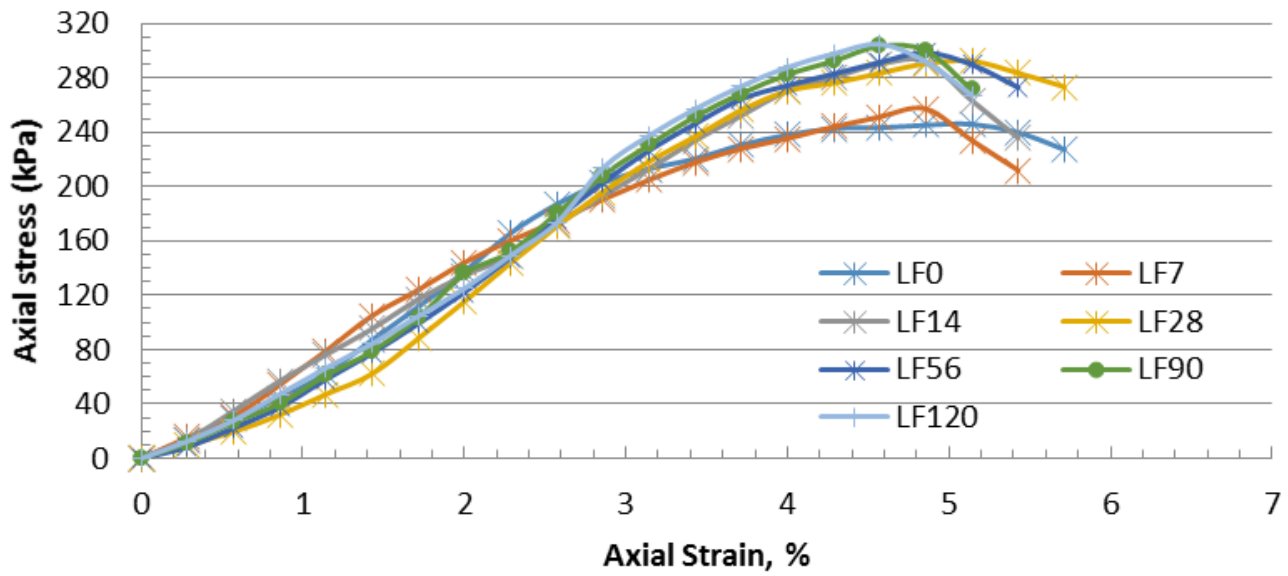

Figure 5 Variation of axial stress $(\mathrm{kPa})$ against axial strain for fiber reinforced lime treated soil specimens at different curing periods

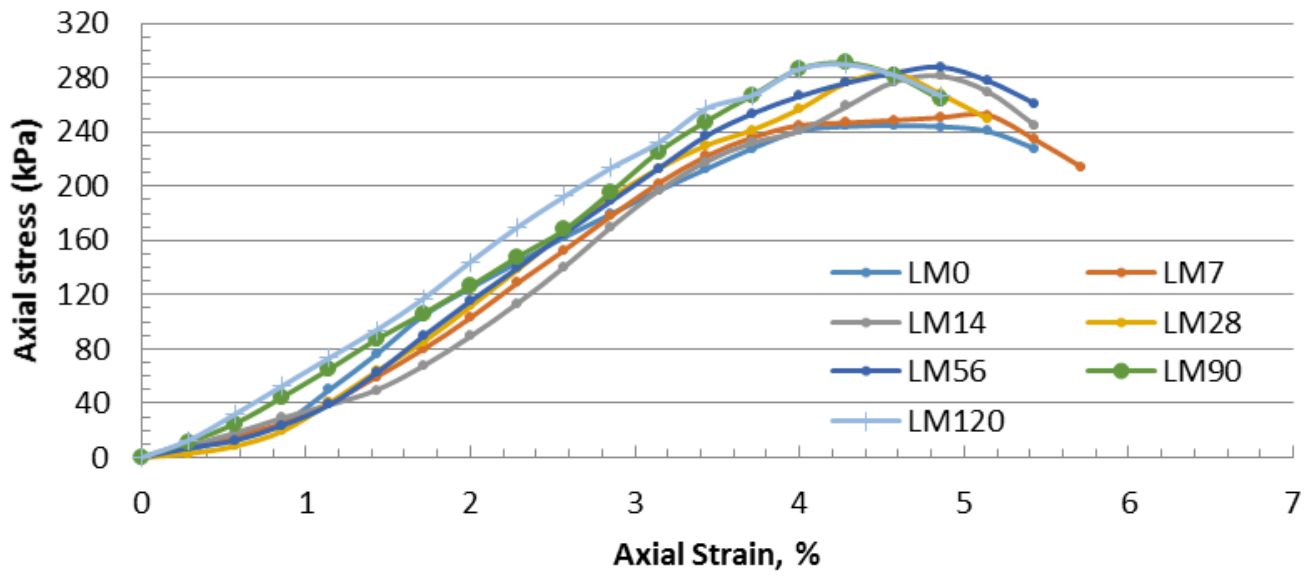

Figure 6 Variation of axial stress $(\mathrm{kPa})$ against axial strain for mesh reinforced lime treated soil specimens at different curing periods

The unconfined compressive strength of fiber reinforced lime treated soil samples are the highest, followed by mesh reinforced lime treated soil samples and lime treated soil samples. This shows that 
fiber reinforcement is more effective compared to mesh reinforcement for this particular case. The results also show that the increment in unconfined compressive strength is less significant (less than $5 \%$ ) after a 28 day curing period. Figure 7 shows the variation of unconfined compressive strength against different curing periods for lime treated, fiber reinforced lime treated and mesh reinforced lime treated samples.

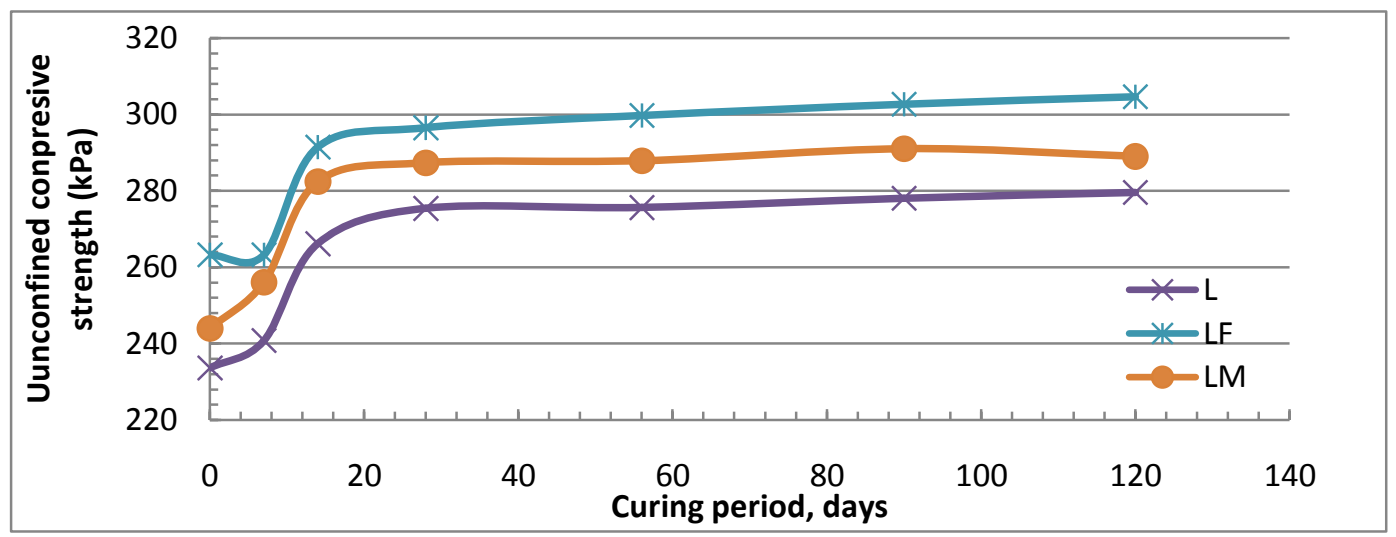

Figure 7 Variation of unconfined compressive strength against curing period for lime treated, fiber reinforced lime treated and mesh reinforced lime treated samples

\subsection{Scanning Electron Micrograph}

Scanning electron micrography was done on untreated soil samples and, after 90 days of curing, on lime treated soil samples, fiber reinforced lime treated soil samples and mesh reinforced lime treated soil samples. Figure 8 to Figure 11 shows the scanning electron micrography mentioned. All the scanning electron micrography were enlarged by 500 times.

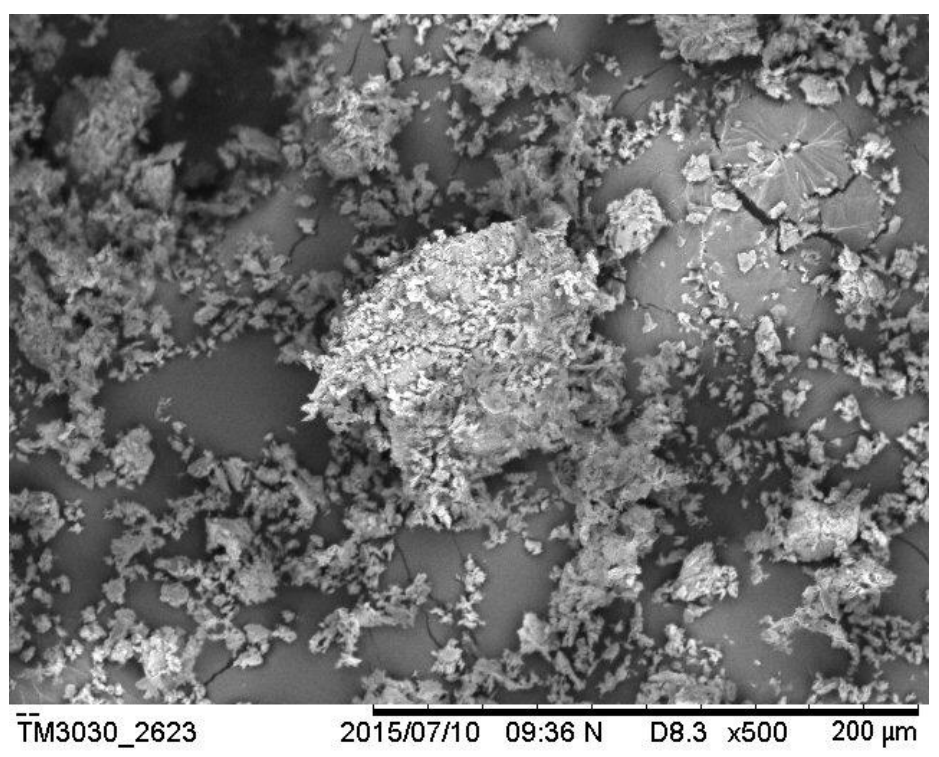

Figure 8 SEM image of untreated soil sample 


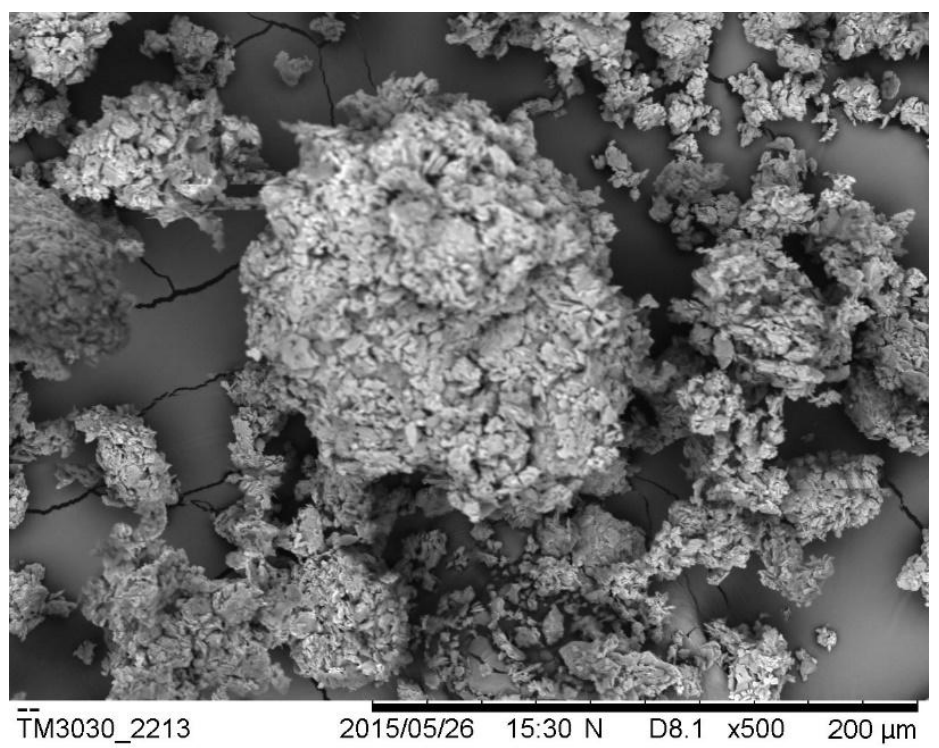

Figure 9 SEM image of lime treated soil sample

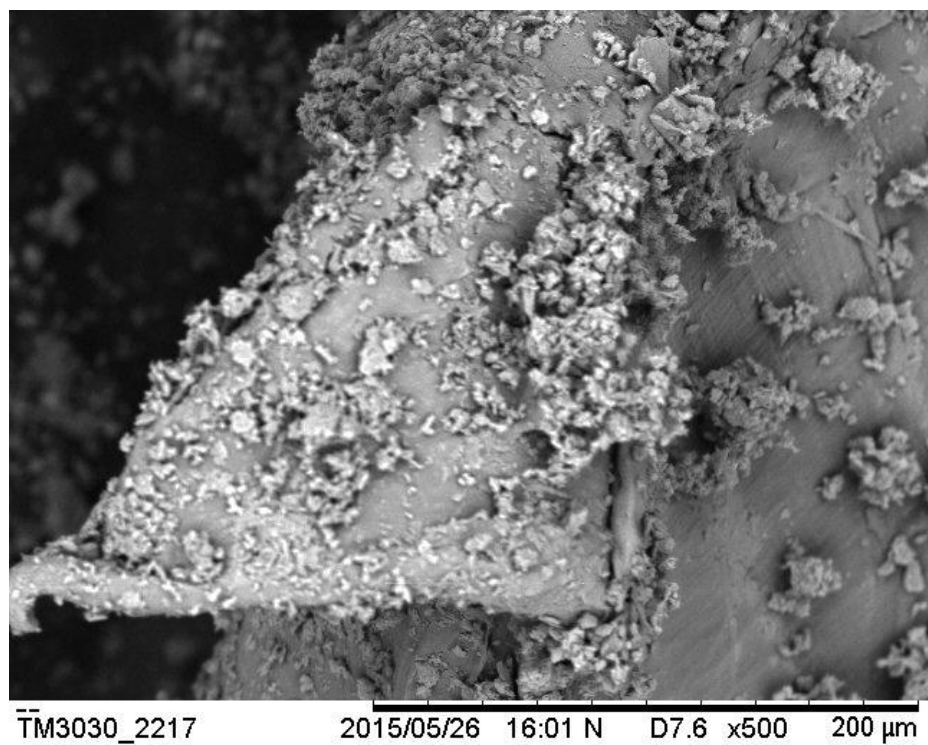

Figure 10 SEM image of fiber reinforced lime treated soil sample 


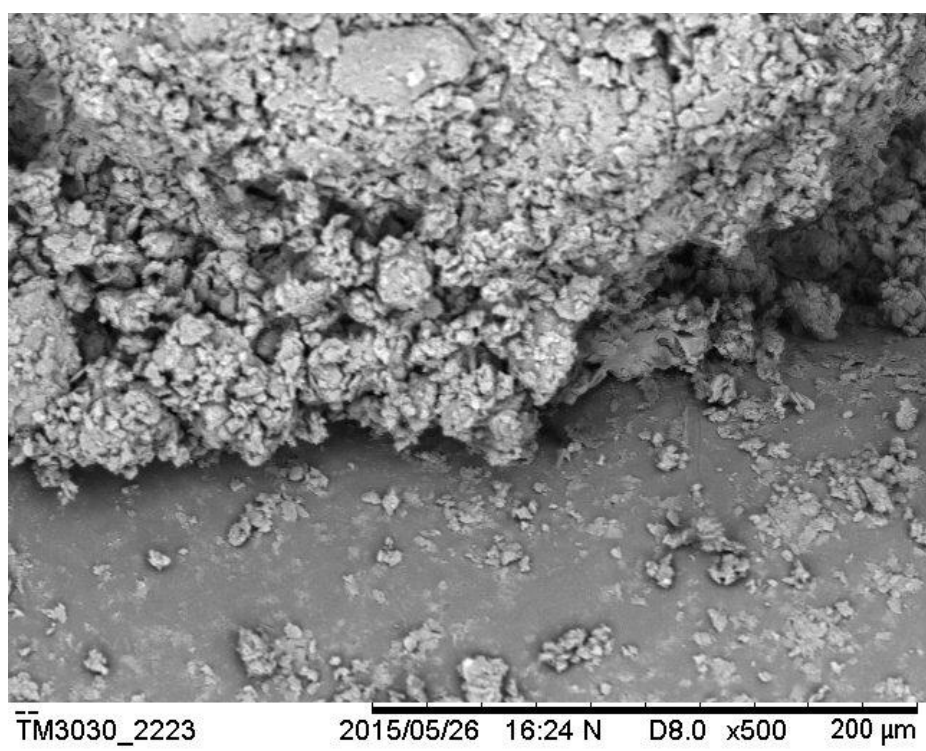

Figure 11 SEM image of mesh reinforced lime treated soil sample

\subsection{CONCLUSION}

The soil sample used in this study is classified as high plasticity elastic silt with sand (MH) using the Unified Soil Classification System (USCS), with organic content of $0.95 \%$. The specific gravity of the soil is 2.58 . The optimum moisture content and maximum dry density of the untreated soil sample are $21 \%$ and $1680 \mathrm{kN} / \mathrm{m}^{3}$ respectively. The optimum moisture content and maximum dry density of the lime treated soil sample are $22 \%$ and $1560 \mathrm{kN} / \mathrm{m}^{3}$ respectively. The unconfined compressive strength of the soil sample increased as curing period increased, but the failure strain of the soil sample decreased as the curing period increased. The pozzolanic reaction that happens during the curing period contributes to the development of strength of the soil sample but the ductility of the treated sample reduced due to moisture loss. Adding fiber and mesh was able to increase the strength and the failure strain as the fiber and mesh was able to interlock with groups of particles and provide tensile force to the soil matrix. The increment of unconfined compressive strength of lime treated soil samples after 28 days of curing period are less significant, at less than $5 \%$.

\section{REFERENCES}

[1] Kolias, S., Kasselouri-Rigopoulou, V., \& Karahalios, A. (2005). Stabilization of clayey soils with high calcium fly ash and cement. Cement Concrete Composite, 27, 301-313.

[2] Sharma, N.K., Swain, S. K., Sahoo, \& U.C. (2012). Stabilization of a clayey soil with fly ash and lime: a micro level investigation. GeotechGeolEng, 30, 1197-1205.

[3] Ahmad, F., Bateni, F., \& Azmi, M. (2009). Performance evaluation of silty sand reinforced with fibres. Geotextiles and Geomembranes, 28, 93-99.

[4] British Standard Institution. (1990). BS 1924, Stabilised Materials for Civil Engineering Purposes. London, UK: British Standard Institution.

[5] British Standard Institution. (1990). BS 1377, Methods of Test for Soils. London, UK: British Standard Institution. 